\title{
APONTAMENTOS SOBRE CURADORIA DE ARTE NA CONTEMPORANEIDADE
}

\author{
Silvia Miranda Meira' \\ Edson Leite
}

DOI: https://doi.org//0265/2/museologia.v7il4.18394

\begin{abstract}
RESUMO
Os discursos das praticas artísticas contemporâneas, aparentemente neutros, em territórios desenquadrados, configuram um conjunto de agentes e atores engajados diretamente com o sentido da arte, que trazem o significado à cena. As metamorfoses contemporâneas trouxeram uma abundância de formas artísticas e uma vasta abordagem de temas onde seus modos de discurso transformaram - locus da arte, em partilha do sensível, engajamento social, e, percepção de mundo. Os subsídios ao entendimento dos conceitos que fundamentam a arte contemporânea são muitas vezes prescritos pelo projeto de curadoria da exposição, o que possibilita aproximar o olhar para o seu entendimento. Da demanda conceitual (projeto de curadoria) ao mis en scène (solução ou prática), as intervenções contemporâneas, passando por ambientações e cenografias que the conferem a visualidade pela crítica e mediação que fornecem informação, se inserem em propostas culturais.
\end{abstract}

\section{PALAVRAS-CHAVE}

curadoria de arte contemporânea, modos operandi da curadoria de arte no contexto contemporâneo, caraterísticas da arte contemporanea

\begin{abstract}
The discourses of contemporary artistic practices, apparently neutral, in unconstrained territories, constitute a set of agents and actors directly engaged with the sense of art, which bring meaning to the scene. Contemporary metamorphoses have brought an abundance of artistic forms and a broad approach to themes where their modes of discourse have transformed the locus of art, sharing the sensitive, social engagement, and world perception. The subsidies to the understanding of the concepts that base the contemporary art are often prescribed by the curatorial project of the exhibition, which allows, to approach the look for its understanding. From the conceptual demand (curatorial project), to mis en scène (solution or practice), contemporary interventions appears through settings that give it visuality, through the critique and mediation that provide information, and are inserted in cultural proposals.
\end{abstract}

\section{KEYWORDS}

contemporary art curator, curating contemporary art, notes of contemporary art

'Livre Docente pela ECA/USP Dra em História da Arte séc. XX / Univ. Paris IV - Sorbonne Especialista em Pesquisa em Arte Contemporânea Conservação Preventiva/ Museu de Arte Contemporânea da Universidade de São Paulo 


\section{Introdução}

A ruptura com o poder hegemônico ditado pela cultura erudita provocou o alargamento do conceito de arte, relacionando-a não só à estética, mas a outros regimes do saber como a antropologia, as ciências sociais, a filosofia, a política, a psicanálise etc. As metamorfoses contemporâneas trouxeram uma abundância de formas artísticas e uma vasta abordagem de temas onde seus modos de discurso transformaram o fluido locus da arte em partilha do sensível, engajamento social e percepção de mundo. Falando uma outra linguagem, a partir de ordens alternativas, do estranhamento, da subversão, do fascínio ou da dissonância, essas metamorfoses contemporâneas aguçam a sensibilidade e a percepção nos aproximando de um estar no mundo, uma mudança na natureza da arte: de questões da aparência lançam questões de existência (MEIRA, 2016).

As formas artísticas contemporâneas plurilógicas e multisensoriais se colocam, atualmente, sem fronteiras entre o interior protegido do museu e a cidade exterior. $O$ movimento da contracultura introduziu a idéia de democratização da arte, a utilização de materiais não nobres no fazer artístico e o desaparecimento da hierarquização, entre outras características, estabelecendo uma nova ordem. Em modos variados de expressão, como site-specifics, intervenções e instalações, instaura-se um desenquadramento do conceito tradicional da arte.

Desde a incorporação das culturas marginais nos anos 60 à História da Arte, a produção artística sofre enfrentamento de seus juízos de valores. A multiplicidade dinâmica de manifestações contemporâneas que se fundamenta a partir do movimento de contracultura (BAUDRILLARD, 1997), transforma o espaço sagrado da arte, de tradição e tradução de conteúdo cultural. $O$ discurso predominante das práticas artísticas da contemporaneidade é o da palavra oculta de sentido, onde encontramos no museu ou na exposição contemporânea, um conjunto de agentes e atores conhecidos como curadores, engajados diretamente com a produção da infraestrutura da arte.

Desenvolvendo atividades de preservação enquanto patrimônio, de catalogação e de pesquisa enquanto acervo, o curador, além de atuar na política de novas aquisições, promove a atualização de coleções e atua na construção de um conceito ou de um determinado tema. Cabe ao curador selecionar e dispor as obras de arte para o público, enfatizando uma abordagem que favoreça a produção de significados e que possa possibilitar reflexões, articulações e contraposições que venham a enriquecer a experiência estética. Como explica Dernie:

\section{Exponer' significa proponer, ofrecer, desplegar el resultado del tra- bajo. Fundalmentalmente, realizar una exposición gira en torno a los contenidos de los trabajos que serán expuestos, cuyo orden de presentación se estrucura en secuencia, de tal modo que puedan comprenderse en relación entre ellos y en diálogo con las condicio- nes del medio que los observe. (DERNIE, 2006, p. 6)}

Agrupando e articulando semelhanças e diferenças visuais ou conceituais (CASTILLO, 2008), o curador determina um conceito ou tema que funciona como fio condutor que organiza a mostra no processo de revelação das obras. O curador é um articulador de sentidos e sua ação se dá no espaço e nas relações, incluindo as obras, os artistas - quando ainda vivos -, o espaço, o espaço simbólico e as instâncias de poder (TEJO, In REZENDE; BUENO, 20I3). 


\section{Um pouco de história}

Nos últimos anos testemunhamos um número crescente de textos e livros sobre curadoria enquanto disciplina jovem tentando definir o campo e expertise da profissão. $O$ termo curador vem da raiz grega "curare", que significa "cuidar de", e pode encontrar as suas origens históricas no Império Romano, onde os curadores eram servidores públicos que exerciam um papel especifico no sistema de administração e códigos legais da sociedade romana. Eram indicados para pessoas incapazes de gerir seus negócios, homens menores de 25 anos, loucos, lunáticos, surdos, mudos, portadores de doenças incuráveis etc. Os curadores eram apontados para pessoas incapacitadas por falha de julgamento ou inadequação de disposição (MADZOSKI, 20I3). O cuidado não era do tipo médico ou humanitário, mas referia-se à posse material e herança. Os curadores eram instituídos como guardiões das propriedades, nos lugares e posições onde existisse algo valioso a ser guardado, protegendo os bens de qualquer tipo de dano, servindo como mediadores do sistema.

Nos tempos modernos, a curadoria nas artes começa por pessoas envolvidas com as coleções dos museus. O curador do museu exercia um cargo vinculado a uma instituição estável, colaborava na construção do patrimônio e cuidava da preservação da coleção permanente. $O$ cargo era relacionado, também, à interpretação da arte e do contexto da coleção. Curadores, como especialistas, deveriam zelar pelos objetos recentemente adquiridos nas coleções mas, muitas vezes, também atuavam para camuflar ou esconder particularidades da história e da origem de algumas aquisições menos éticas ou lícitas."Os museus em geral, têm uma lógica de funcionamento e demandas internas e externas que escapam de uma decisão curatorial” (ALVES, In REZENDE; BUENO, 20I 3, p. 250).

Nas décadas posteriores à Segunda Guerra Mundial houve uma mudança nesse tipo de curador de museu para o que viria a se chamar autor de exposição, ou seja, o papel do curador como entendemos na atualidade. $O$ autor de exposições era menos relacionado com a preservação da arte e mais preocupado em descobrir artistas, novos talentos, dava aval ao reconhecimento de estilos e garantia de qualidade.

O termo autor, segundo Foucault (1998), define o criador genial de um trabalho no qual deposita com potência e infinita generosidade um mundo inesgotável de significados. A partir do conceito de curador como autor de exposições, a figura do curador se torna o de ter responsabilidade pela atividade múltipla de produtor, mediador, responsável pela interface e critica de arte.

\section{A curadoria contemporânea}

Os papeis de crítico, curador, professor e artista, embora diferentes e bem definidos, se misturam muitas vezes, especialmente no Brasil, apresentando contextos próprios que constituem uma narrativa de tessitura experimental. $A$ prática curatorial na condição contemporânea induz a um modo de pensar que reforça a demarcação de posições mais definidas para lidar com o questionamento e reelaboração das obras de arte. Contudo, cabe ressaltar que a atuação curatorial envolve um exercício crítico que se torna concreto na exposição.

Curadores pesquisam, escrevem, articulam conceitos, levantam fundos, planejam, dirigem a produção, criam obras, cuidam de artistas, obras e exposições, desde seu estágio inicial como ideia/projeto até muito depois que acontecem, como história (MADZOSKI, 20I4). Os curadores têm obrigação de assegurar que os artistas não sejam retirados da cena ou tratados injustamente e, 
neste sentido, promovem, apresentam e representam os artistas formando redes, reunindo ideias, documentos e construindo públicos, trabalhando de forma independente, dentro do museu e através dele em relação a instituições e fora delas, motivando a circulação dentro do sistema da arte e agindo como atores, pêndulos entre a prática e a teoria, entre a arte e sua história, entre a crítica e a mediação (RIFKY, 20I I).

O pensamento curatorial através da partilha com o sensível se propõe a conectar a produção artística com a recepção do público.A curadoria de exposições de arte na contemporaneidade assume a responsabilidade perante seu público como mediadora de entendimento veiculando os conceitos propostos da enunciação do artista nas condições de fala das produções contemporâneas.

O curador não é um autor no sentido isolado, seu processo de trabalho depende das conexões que estabelece como agente mediador. Ele depende da rede de relações na qual está inserido (CARVALHO, 20I4). O curador contemporâneo ocupa uma posição poderosa de influência e controle da produção artística (MADZOSKI, 20।4).A atuação do curador compreende, muitas vezes, a visita aos ateliês, a análise e reflexão sobre a produção dos artistas, buscando as reverberações do fascínio destes contatos que envolvem a intimidade, a rotina do artista e a essência da criação. As novas tecnologias comprimem o tempo e atualizam vertiginosamente as informações sobre os experimentos artísticos próximos e distantes, efêmeros e produzidos em suportes mais tradicionais.

A arte emerge não só como pintura, escultura, desenho e gravura, mas a partir da fotografia e dos meios tecnológicos. A investigação criativa dá lugar a processos de mestiçagem, combinações de técnicas, apropriação de materiais, agrupamento de procedimentos e a simultaneidade de recursos evoca, em sua forma aparente, a construção de um lugar que não acaba.

O mercado pode trazer fragilidades estruturais ao circuito da arte, especialmente no que se refere à constituição de acervos de coleções públicas. Ele também pressiona para que haja uma constante troca nas mostras, limitando as possibilidades dos museus manterem o convívio constante com o trabalho de artistas, tornando possível o diálogo com o público não especializado.

O curador deve problematizar conceitos a partir da seleção das obras a serem expostas, estabelecendo relações e diálogos entre as obras, de maneira a possibilitar um entrosamento entre as obras e o público.

Esse 'ponto de vista' do curador não significa, de forma alguma, que seja essa a forma mais acertada de ver determinada, tendência ou determinado artista, porém simplesmente reflete um enfoque individual, passível de posterior revisão ou confronto (AMARAL, 2006, p.52).

O recorte realizado pelo curador revela, geralmente, um ponto de vista crítico relacionado a questões técnicas, intelectuais, poéticas e estéticas que podem favorecer as experiências estéticas do público através do conceito expositivo. $O$ curador, a partir dos recursos e limitações econômicas e espaciais, realiza seu trabalho concebendo uma concepção artística a partir de suas pesquisas, sua rede de colaboradores, seus parceiros, seu possível contato com os artistas e instituições, de forma a solucionar as necessidades das obras e da exposição.

As especificidades das obras devem ser consideradas pelo curador que, com sua abordagem pessoal, estabelece um método determinado para tratar as questões propostas pelas obras, levando em consideração a história da arte e as possibilidades do discurso curatorial. $O$ curador identifica aspectos, agrupa 
informações e cria conexões (OBRIST, 20I0) para prover uma exposição que envolveu escolhas, pesquisas e decisões, muitas vezes pouco evidentes para o público que absorve a exposição e as facilitações e reflexões propiciadas pelo curador sem se dar conta. Afinal, a curadoria deve ser uma atividade meio, cujo objetivo é a aproximação entre o público e a obra do artista.

Observando a curadoria como uma possibilidade de materializar formulações de pensamentos tanto históricos quanto críticos e temáticos, os curadores tornam-se operadores da subjetivação dos objetos seguindo a supremacia da razão, entre outras. Sua posição no sistema atual da arte contemporânea é ambígua, pois de cuidador de exposição ele se transforma em produtor de infraestrutura, na construção de novos territórios e laboratórios de percepção, o que significa que:

- Apresenta as especificidades do contexto em que os objetos/obras são apresentados enquanto arte - ordena os horizontes de signos e significantes da situação arte e introduz o tipo de discurso;

- Contextualiza a singularidade da operação artística a partir dos antecedentes conceituais do repertório utilizado pelo artista, e alocada na situação arte;

- Justifica através de teorias e disciplinas alocadas as particularidades do discurso;

- Promove a legitimação do enunciado através de textos críticos e conceitos desenvolvidos pelo artista.

O declínio da figura do crítico, que deixa de ser o detentor de narrativas, legitimadas nas verdades consagradas pela história, colaboram para tornar o curador, aquele que legitima a obra através da situação expositiva. Um recorte curatorial representa a escolha de uma das possibilidades de inscrição de uma obra no circuito expositiv. $O$ curador funciona, portanto, como um legitimador da inserção do artista no espaço da exposição. A curadoria e suas condicionantes implicam também na inserção no sistema da arte. A obra, a montagem e o lugar da exposição não são neutros. Há uma grande complexidade entre estes vários imaginários e não há isenção, nem distanciamento na validação das obras e dos artistas através da curadoria.

A atividade do curador em exposições de arte, tal como a reconhecemos na atualidade, teve início, internacionalmente, a partir dos anos 1960. Foi o início de uma profissão de prestígio e poder que substituiu a função do diretor artístico e diferentemente do crítico, esse novo personagem, denominado curador, tem menos autonomia sob a perspectiva de sua vinculação às instâncias de poder uma vez que precisa estar sempre em negociação com estas instâncias.

O desenvolvimento de um curador autoral não foi aceito sem resistência. A exposição 'Quando as Atitudes se tornam Forma' organizada pelo lendário Harald Szeeman em Berna, na Suíça, em 1969, é ainda hoje uma das mais citadas e discutidas exibições de arte dos últimos cinquenta anos. Através de uma constelação internacional de artistas experimentais, como Joseph Beuys, Robert Morris, Richard Serra, Eva Hesse e Bruce Nauman, entre outros, a exposição apresentou idéias, conceitos, processos e situações cujo caráter provisório, imaterial e inacabado, provocou controvérsia entre os críticos e o público de Berna que teve dificuldades para compreender as obras. Esta exposição modificou a função do curador, que deixou de ser a pessoa que zela pelo acervo dos museus para se tornar aquela que concebe e realiza exposições. 
A figura agenciadora do curador responde as demandas de seu tempo preenchendo as etapas da estratégia de produção da arte.Algumas das características que configuram a Arte Contemporânea na atualidade pedem o agenciamento de um curador, a exemplo: o artista como teórico, a participação ativa do público, a obra como um evento, intervenção aleatória no meio ambiente, projetos realizados em locais ermos e inacessíveis, projetos experimentais de vídeoarte, entre outros. Exposições que se opõem à ideia clássica do museu como um local de colecionismo e que o transformam em casa de experiências, por exemplo, necessitam da contextualização do curador autoral.

As intervenções artísticas contemporâneas, em lugares incertos, abrem a percepção ao entorno, ao intercâmbio com símbolos escritos no espaço. Olhar as obras contemporâneas reivindica o lugar do vivido em seu engajamento com o artístico. A subversão estabelece outro enfoque sobre os roteiros artísticos, ela insere um processo de reflexão crítica.

Em vez da arte do artista se tornar parte de uma multiplicidade de trabalhos exibidos em conjunto em um espaço, suas obras na contemporaneidade perdem sua relação com a origem e são refeitas como parte do discurso artiIhado de outro. Anônima e dessacralizada, a experiência oferece uma narrativa fragmentada, enviesada e, muitas vezes, perversa a ser capturada por quem vê.

A sobreposição e o entrechoque de significados instigam os processos de significação, espelhando como os modos contemporâneos se articulam. Sugerem ao exercício do olhar, uma organização entre os elementos que perturbam a sua continuidade, criando possíveis elos de aproximação e compreensão à memória. A inexistência de regras convencionais para o fazer artístico tem demonstrado como a arte é construída através de um sistema de circulação entre a curadoria de exposições, na qual a obra tem o seu lugar em coleções do circuito da arte, meio que compõe a difusão e a crítica e através do respectivo público.

\section{A questão brasileira}

A ausência de uma formação profissional sistemática entre os artistas brasileiros faz com que bienais e exposições internacionais se constituam em locais importantes de compartilhamento e absorção de valores estéticos, alargando as fronteiras do meio artístico nacional. A importância da atualização da inteligência artística foi sempre uma grande preocupação dos artistas, frente ao academismo e o provincianismo latente. Os movimentos de vanguarda europeus e americanos interviram de maneira decisiva na renovação da linguagem visual da arte brasileira (Meira, 20l6).

Nossas fronteiras históricas foram marcadas pelo atravessamento como troca cultural que selecionou, modificou e recombinou etnias tradicionais e aculturação predatória, imitação e inovação, fundindo local e global em suas produções artísticas. $\mathrm{Na}$ atualidade o grande desafio é a tolerância e a aceitação, o compartilhamento e a convivência, uma poética da diversidade e não uma política de diferenciação.

As artes visuais passam por um pensamento articulado, contextualizado pela história da arte, incluindo as noções de modernidade, brasilidade e recepção internacional da arte brasileira. A busca de identidade dos artistas brasileiros através das bienais e feiras internacionais evidenciou outras possibilidades de discurso e revelou gerações de artistas que buscaram reconhecimento através de outras vias. 
A malícia nativa brasileira procura experimentar outras soluções como visão de mundo, colocando em crise a ideia de raízes, tradições e autenticidade, até mesmo o conceito de nação pode ser colocado de lado nas designações sobre arte. A arte contemporânea caminha contaminada pela cultura visual, densa de referências onde para o mestiço a questão da identidade não faz sentido. Cabe ao curador que trabalha com artistas no Brasil, ter em mente as questões da mestiçagem, das combinações, do sincretismo, e dos fragmentos que remodelam as escritas lineares da arte com liberdade expandida em suas significações, promovendo o entendimento do eclético, sem tropeçar em critérios ou julgamentos estéticos (MEIRA, 2016a).

\section{Considerações finais}

O termo curadoria se banalizou e passou a ser empregado para qualquer atividade relacionada ao "agenciamento de produtos" (ALVES, In REZENDE; BUENO, 20I3, p. 242) como a organização de eventos, concertos, mesa de debates, página na internet, promoção de tendências etc. $A$ atividade do curador de arte tem perdido, desta forma, o seu principal atributo que é o de propiciar o lugar para a reflexão.

O vetor cronológico é apenas uma das possibilidades da análise das obras e das curadorias de uma exposição.A cronologia é principalmente um ponto de partida que auxilia evitando erros históricos. As referências à história da arte não são as únicas utilizadas pelos artistas e identificadas pelo público. $O$ contexto social e histórico, entre outros, dos atores envolvidos é fundamental para a apreensão cultural de uma ação curatorial. A curadoria busca contextualizar o objeto de arte e o texto do catálogo constitui uma pesquisa que legitima o pertencimento das obras a exposição.

A interatividade marca a criação artística, onde a obra arquitetônica e teatral se coloca como um evento, uma descoberta do que vemos a partir daquilo que nos olha. A experiência sensível estimula o espectador diante da situação embaralhada, da metáfora desordenada ou da intervenção inusitada, aproximando o olhar para o seu entendimento.

\section{Referências}

AMARAL, Aracy A. Textos dos trópicos de capricórnio: Bienais e artistas contemporâneos no Brasil, 2006.

BAUDRILLARD, Jean. A Arte da Desaparição. Rio de Janeiro: UFRJ: Núcleo de Tecnologia da Imagem, 1997.

CARVALHO, Ananda. Redes Curatoriais: procedimentos comunicacionais no sistema da arte contemporânea. Dissertação (mestrado em Comunicação e Semiótica), Pontifícia Universidade Católica de São Paulo, 2014.

CASTILLO, Sonia Salcedo Del. Cenário da arquitetura da arte. São Paulo: Martins Fontes, 2008.

DERNIE, David. Espacios de exposición. Barcelona:Annablume, 2006.

FOUCAULT, Michel. Aesthetics, Method, and Epistemology. New York: The New York Press, 1998.

MADZOSKI,Vesna. De Crratoribvs: da Roma Antiga aos tempos modernos. New York; Dresden, Antropos Press, 2013.

. A Invenção dos curadores, In BARTHOLOMEU, Cezar; TÁVO- 
RA, Maria Luisa (Ed.). Arte \& Ensaios n. 28, Rev. Do PPGAV; EBA; UFRJ, dez 20I4, P. I44-I65.

MEIRA, Sílvia. A Estética Contemporânea. In AQUINO,Victor (Org.). Revista Estética. São Paulo:Afetos Estéticos, n. I3, jul-dez, 2016, p. I-I9.

Apresentação. In POUSADA, Carmen (Org.). Arte Brasileira na Contemporaneidade. São Paulo: Ornitorrinco, 2016a.

OBRIST, Hans Ulrich. Uma breve história da curadoria. São Paulo: BEI Comunicação, 2010.

REZENDE, Renato; BUENO, Guilherme (Orgs.). Conversas com curadores e críticos de arte. Rio de Janeiro: Circuito, 2013.

RIFKY, Sarah. “What do you do exactly?”, Al-Mas-ry Al-Youm, I0 Jannuary $201 \mathrm{I}$. Disponível em: <http://www.almasryalyoum.com/en/node/29|66|>. Acessado em: I5 de junho de 2017. 